\title{
Editorial
}

\section{Resolution of Tax Issues: A Survey of the State of the Art in Japan}

Toshiaki Katsushima, Deloitte Touche Tohmatsu, Tokyo

I would like to take this opportunity to compare and contrast the approaches taken in Japan and the United States toward resolving tax issues. In Japan, the basic approach is to take a set of general tax principles and/or policy directive set forth by the tax authorities and apply such guidance to a particular fact pattern. In contrast to the US policy of attempting to resolve an issue by promulgating a specific ruling or regulation, the approach in Japan is more conceptual. As a result, the answer under Japanese tax law tends to turn on what the NTA's thinking is on a specific matter, as opposed to turning to a specific cite in a regulation or ruling. Let me give a few examples in this regard.

One common issue relates to whether a cost-plus structure can be used in setting up Japanese operations. Where a company functions as a service provider, it is possible to use the so called cost-plus method. As a matter of practice, the NTA generally permits the cost-plus method to be used for calculating an arm's length profit price for the performance of technical services and certain low-value marketing services. A profit mark-up in the range of 5 per cent to 15 per cent is generally acceptable, depending on the particular circumstances. With respect to marketing/sales services, the NTA has allowed the use of the cost-plus method for calculating an arm's length service fee when the marketing/sales service are supportive in nature or the operations are 'small' (undefined). There is, however, no specific guidance as to when the cost-plus method is no longer the appropriate method for pricing marketing/sales services.

On another point, several years ago, officials in the Japanese tax authority (NTA) concluded in a published question and answer circular that the revenue from the sale of prepackaged, standardized software products should not be viewed as license royalties. Consequently, no Japanese withholding tax would be imposed on this revenue. This position has not, however, been announced as an official NTA position. Accordingly, it is not 'definitive' whether proceeds from the 'license' of intangible property, i.e. standardized software products, should be viewed as royalties or sales income.

Another big issue is cost-sharing. The NTA has not issued an official pronunciation related to cost-sharing. Cost-sharing arrangements are, however, permitted in practice. In my experience, the primary issues encountered with regards to cost-sharing arrangements relate to determining a reasonable standard for cost allocation and determining if the allocated costs should include a profit element. Because there is only scant authority available and acceptance of cost-sharing is based on practice, it is difficult to say with any certainty that cost-sharing payments made by a Japanese participant are deductible and can be made free of withholding tax.

An issue I often encounter relates to the application of tax treaty non-discrimination clauses to the Japanese thin capitalization rules. Because Japan's thin capitalization legislation only applies to indebtedness provided by foreign shareholders, the issue of whether protection under tax treaty non-discrimination clauses exists must be raised. The NTA has publicly commented that it believes the law follows the OECD thoughts on appropriate thin capitalization guidelines. Further, the NTA notes that the comparable company exception provides foreign companies with a way to establish bona fide debt. Thus, according to the NTA, discrimination does not exist. However, there is not much guidance as to how the comparable company exception can be applied. For example, how does one find a single most 'comparable company' and will the NTA accept advance determination in this area?

Another big concern these days is 'treaty-shopping'. I think it is noteworthy that no Japanese treaty contains a specific provision against treaty shopping. However, I understand that certain officials at the NTA believe that if multinationals attempt to take advantage of 
treaty shopping, there would be governmental efforts to prevent it. In my experience, if the NTA perceives or suspects that transactions are primarily motivated by tax savings, it will closely scrutinize the transactions and the related parties involved with the intention of discouraging use of the structure, even if there is no clear legal basis for challenge of the tax consequences. As there is no guidance as to how statutory anti-abuse provisions such as Article 11 of Corporate tax law (form versus substance) would apply in this regard, the solution is to make an educated guess drawing upon experience or to have an informal discussion with the NTA.

In the area of financial products, I think that growth has outpaced guidance in Japan's derivative market. Except for certain rules relating to foreign currency exchange gains and losses, there is little authority on the taxation of derivatives. For instance, it is not yet clear if the recipient of an up-front swap payment can allocate the amount ratably over the entire swap period. And how are securities lending transactions to be taxed? Like the above examples, we must seek to determine how the NTA would rule based on application of a set of general tax principles or through conversations with NTA officials.

In the US resolution of these issues would take the form of a lengthy ruling or a set of regulations with a myriad of examples. Consider, for instance, the recently promulgated anti-conduit regulations, the earnings stripping regulations and the transfer pricing regulations. In Japan, these types of issues are generally dealt with by the NTA issuing an unofficial position paper or a policy directive. The job of the Japanese tax practitioner is then to understand the NTA's reasoning and determine how such logic would apply to a specific set of facts.

As I watch the US tax practitioners in my firm, their desks covered with rulings and cases and regulations, struggle with solving a US tax problem, I begin to wonder which approach is better. While there is more uncertainty in the area of Japanese taxation as opposed to US taxation, I think that the price for having more certainty is not one I would be willing to pay. Rather than trying to find a specific answer in a book or document, I much prefer discussing issues with the NTA or looking into my crystal ball to determine how the NTA might rule, even if it means the conclusion is less than definitive. 